\title{
HIPOPLASIA CEREBELAR E PORENCEFALIA EM BOVINOS CHAROLÊS NO SUL DO RIO GRANDE DO SUL
}

\author{
CEREBELLAR HYPOPLASIA AND PORENCEPHALY IN CHAROLAIS CATLLE \\ IN SOUTHERN BRAZIL
}

\author{
Ana Lucia Schild ${ }^{1}$ Franklin Riet-Correa $^{2}$ Cristina Gevehr Fernandes ${ }^{3}$ \\ Maria Cecília Damé ${ }^{4}$ Dominguita Lühers Graça ${ }^{5}$
}

\section{- RELATO DE CASOS -}

\section{RESUMO}

Descrevem-se dois casos de hipoplasia cerebelar congênita observados em terneiros da raça Charolês, pertencentes a um estabelecimento localizado no município de Capão do Leão. Um dos animais apresentava sinais clínicos cerebelares ao nascimento, caracterizados por severa incoordenação motora, hipermetria e tremores de intenção, principalmente da cabeça e do pescoço. O outro animal não conseguia manter-se em estação $e$ apresentava opistótono acentuado. As lesões macroscópicas caracterizaram-se por hipoplasia cerebelar, observando-se apenas remanescentes das regiões do flóculo e do paraflóculo cerebelares e uma cavidade preenchida por líquido e recoberta pelas leptomeninges, que estavam aderidas aos resquícios das folhas cerebelares. Ao corte do encéfalo, havia hidrocefalia discreta e a presença de cavidades císticas (porencefalia). São discutidas as possíveis etiologias, sugerindo-se a possibilidade de que a enfermidade tenha sido causada pelo vírus da diarréia viral bovina-doença das mucosas, apesar dos resultados negativos da imuno-histoquímica realizada em fragmentos do cerebelo dos animais doentes para detecção desse vírus.

Palavras-chave: hipoplasia cerebelar, cerebelo, bovinos, malformação.

\section{SUMMARY}

Two cases of cerebellar hypoplasia in Charolais calves from a herd of a farm located in the municipality of Capão do Leão, Southern Brazil are described. One calf with cerebellar clinical signs at birth, showed incoordination, hypermetria and intention tremors, mainly in the neck and head. The other calf was recumbent with opisthotonos. The gross lesions were characterized by cerebellar hypoplasia, with only remnants of cerebellar floculus and parafloculus and an expanded fluid-filled space covered by leptomeninges. Mild hydrocephalus and porencephaly were observed in the cerebrum. It was discussed the possible etiologies and suggested the possibility of the disease has been caused by bovine viral diarrhea-mucosal disease (BVD-MD) virus despite of negative results of imuno-histochemical technique for detection of this virus in cerebellar fragments of the affected calves.

Key words: cerebellar hypoplasia, cerebellum, cattle, malformation.

\section{INTRODUÇÃO}

Hipoplasia cerebelar é o defeito congênito do sistema nervoso central (SNC), mais freqüente-

\footnotetext{
${ }^{1}$ Médico Veterinário, Doutor, Laboratório Regional de Diagnóstico, Faculdade de Veterinária, UFPel, Campus Universitário s/n, 96010900, Pelotas, RS. E-mail: alschild@zaz.com.br . Autor para correspondência.

${ }^{2}$ Médico Veterinário, Departamento de Medicina Veterinária, Professor Titular, Laboratório Regional de Diagnóstico, Faculdade de Veterinária, UFPel, Pelotas, RS.

${ }^{3}$ Médico Veterinário, MSc., Professor Assistente, Departamento de Patologia, Faculdade de Veterinária, UFPel, Pelotas, RS

${ }^{4}$ Médico Veterinário, Técnica do CPACT/EMBRAPA, Capão do Leão, RS.

${ }^{5}$ Médico Veterinário, Professor Titular, Departamento de Patologia, Centro de Ciências da Saúde, UFSM, Santa Maria.
} 
mente observado nas espécies domésticas, existindo algumas evidências de ser geneticamente determinado em algumas raças bovinas (O'SULLIVAN \& McPHEE, 1975), eqüinas e em cães chow chow (JUBB et al., 1993). A forma melhor definida de ocorrência da enfermidade, entretanto, é a causada pela infecção do cerebelo em desenvolvimento por certos vírus, particularmente o parvovírus felino, o vírus da diarréia viral bovina (BVD-MD), o vírus da enfermidade da fronteira e o vírus da peste suína (JUBB et al., 1993).

Hipoplasia cerebelar produz sinais clínicos que variam entre uma ataxia discreta ou quase imperceptível nos animais recém-nascidos, até a completa ausência de coordenação e inabilidade de manter a postura normal. Animais severamente afetados são incapazes de se manter em pé e assumem variadas posições, incluindo opistótono. $\mathrm{O}$ tônus muscular está normal e os animais respondem normalmente à estimulação sensorial. Tremores da cabeça e nistagmo podem ser, também, observados. Durante as primeiras semanas de vida, pode haver melhora nos sinais clínicos por mecanismos de compensação. A severidade dos sinais clínicos nem sempre é indicativa da severidade da hipoplasia cerebelar ou degeneração observadas na necropsia (KAHRS et al., 1970).

As expressões anatômicas da hipoplasia, tanto no cerebelo como nas estruturas subcerebelares, são variáveis, porém essa variação é mais em grau do que em tipo. Em alguns casos, o cerebelo pode estar aparentemente normal e o defeito ser detectado apenas microscopicamente. DONE et al. (1980) mencionam que a razão entre o peso do cerebelo e do cérebro completo em animais normais pode variar de $8,30 \%$ a $11,01 \%$.

$\mathrm{Na}$ raça Shorthorn foi descrita hipoplasia cerebelar, de provável origem hereditária, sem evidências macroscópicas de diminuição do tamanho do cerebelo em três de quatro animais afetados, com lesões histológicas caracterizadas por baixa densidade celular na capa granular de algumas folhas, número reduzido de células de Purkinje e capa molecular mais estreita que o normal (O'SULLIVAN \& McPHEE, 1975; SWAN \& TAYLOR, 1982). Por outro lado, nessa mesma raça, existem relatos de hipoplasia cerebelar com acentuada diminuição de tamanho do cerebelo e com lesões histológicas caracterizadas por reduzido número de células na capa granular, capa molecular estreita e algumas células de Purkinje com vacúolos, porém, sem evidência de perda das mesmas (FINNIE \& LEAVER, 1965).

A infecção de vacas prenhes suscetíveis, entre o período inicial da gestação até o final do primeiro terço, pelo vírus da BVD-MD pode resultar em morte fetal, aborto, morte neonatal ou em uma variedade de distúrbios do desenvolvimento, entre os quais predominam os defeitos neurológicos e oculares (BROWN et al., 1974; JUBB et al., 1993). Os efeitos da infecção por esse vírus, portanto, estão relacionados ao momento da gestação, e o aumento da resistência está associado à maturidade fetal. A atividade mitótica das células da capa germinativa externa são especialmente vulneráveis aos efeitos dos agentes teratogênicos e o vírus causa necrose seletiva dessas células. Esse processo destrutivo pode ser aumentado pelas lesões vasculares que são, também, determinadas pelo vírus (JUBB et al., 1993).

As infecções que ocorrem dentro dos primeiros 100 dias de gestação tendem a ser letais resultando em aborto ou mumificação (JUBB $\boldsymbol{e t} \boldsymbol{a l}$., 1993). Hipoplasia cerebelar congênita, caracterizada por sinais neurológicos que variam desde uma leve ataxia até a completa inabilidade de manutenção da postura normal, ocorre seguindo a infecção natural ou experimental de vacas prenhes entre os 102 e os 183 dias de gestação (KAHRS et al., 1970).

Casos espontâneos de hipoplasia cerebelar associada à infecção pelo vírus da BVD-MD foram descritos, também, na raça Holandesa, sendo observadas malformação e redução do tamanho do cerebelo e lesões histológicas caracterizadas por cavitação da substância branca, redução das células de Purkinje e células da capa granular e desorganização do córtex cerebelar, alternando-se com algumas folhas cerebelares de aspecto normal e áreas de redução da mielina (WILSON et al., 1983).

No Rio Grande do Sul, o vírus da BVDMD tem sido isolado de terneiros e de soros de neonatos coletados em matadouros, sendo estimado que cerca de $50 \%$ a $70 \%$ do rebanho gaúcho já teve contato com o vírus (RIET-CORREA et al., 1996).

Os objetivos do presente trabalho foram descrever os sinais clínicos e a patologia de dois casos de hipoplasia cerebelar observados em um rebanho da raça Charolesa, bem como discutir as possíveis etiologias da enfermidade.

\section{RELATO DO CASO}

A enfermidade foi observada em dois terneiros da raça Charolês pertencente ao Centro de Pesquisa Agropecuária de Clima Temperado (CPACT/EMBRAPA), localizado no município de Capão do Leão. Os dois animais que apresentaram sinais clínicos da enfermidade foram necropsiados, e fragmentos de todos os órgãos e o sistema nervoso central foram fixados em formol a $10 \%$, incluídos em parafina, cortados com $6 \mu \mathrm{m}$ de espessura e cora- 
dos pela técnica de hematoxilina e eosina e azul rápido de luxol. Em secções do cerebelo, incluídas em parafina, foi utilizada técnica imunoistoquímica avidina-biotina para a detecção de antígenos virais utilizando anticorpo monoclonal anti vírus da BVDMD $^{\mathrm{a}}$ (CESAR, 1996).

\section{RESULTADOS}

Os dois animais afetados nasceram nos meses de janeiro e novembro de 1995 e eram filhos de pais diferentes e sem relação de parentesco entre si, sendo um proveniente do município de Rio Grande e o outro de Camaquã. $\mathrm{Na}$ propriedade, eram criadas outras raças bovinas e o manejo utilizado era idêntico para todos os animais. O rebanho Charolês permanecia durante todo o ano em áreas de campo nativo ou em restevas de diferentes cultivos como soja, arroz e sorgo.

$\mathrm{O}$ primeiro terneiro afetado apresentava severa incoordenação motora e, quando excitado, andava com os membros afastados lateralmente do corpo, apresentava hipermetria (Figura 1) e batia-se involuntariamente contra cercas e objetos. Apresentava tremores de intenção, principalmente da cabeça e do pescoço e quando caía girava várias vezes sobre o próprio corpo até conseguir levantar-se. Apesar dos sinais clínicos severos, o animal era capaz de alimentar-se. O segundo terneiro afetado não conseguia manter-se em pé e apresentava opistótono acentuado.

Os dois animais foram sacrificados e, às necropsias, observou-se que o primeiro animal apresentava os hemisférios cerebrais com circunvoluções pouco definidas e severa hipoplasia cerebelar (Figura 2), observando-se apenas remanescentes da região do flóculo cerebelar e uma cavidade preenchida por líquido e recoberta pelas leptomeninges, que estavam aderidas aos resquícios das folhas cerebelares.

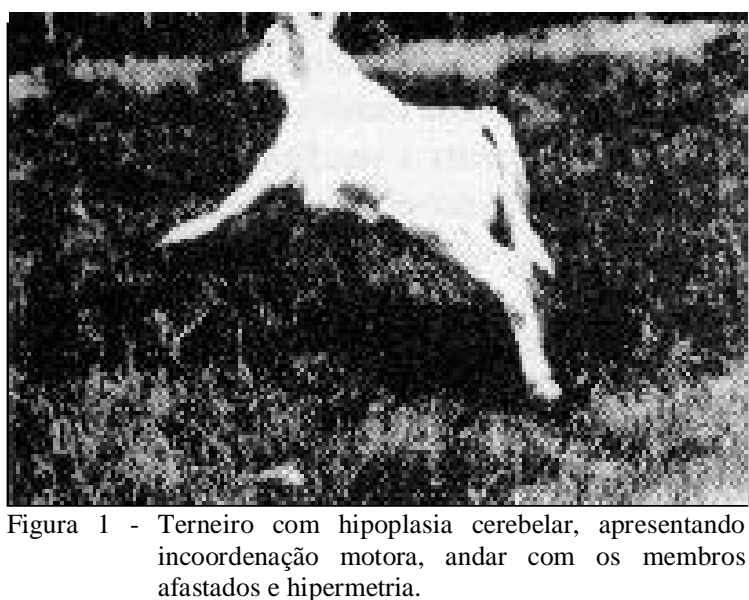

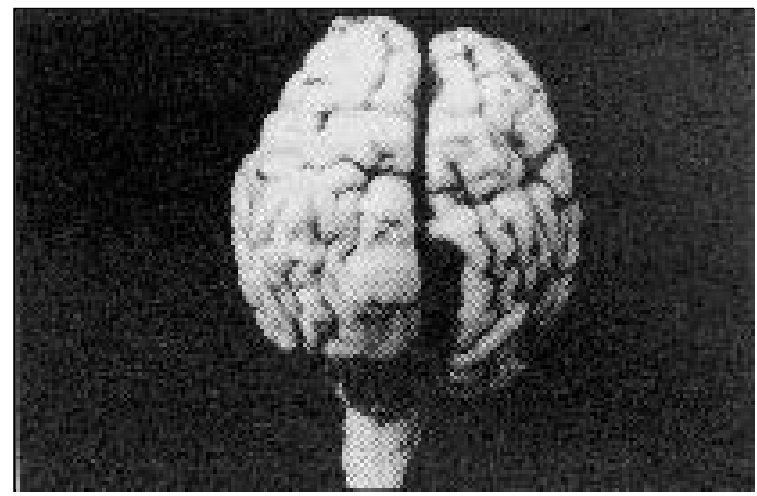

Figura 2 - Hipoplasia cerebelar. São observados resquícios do tecido cerebelar hipoplásico.

Não havia medula cerebelar e tampouco observavam-se os pedúnculos cerebelares ligando o órgão à ponte. Ao corte do encéfalo havia hidrocefalia discreta e a presença de uma cavidade cística (porencefalia), em forma triangular, com o lado maior medindo aproximadamente $5 \mathrm{~mm}$ de diâmetro na substância branca, estendendo-se desde o lobo frontal direito até a região do hipocampo, seguindo daí bilateralmente simétrica até a região posterior do córtex. $\mathrm{O}$ outro terneiro apresentava, também, acentuada hipoplasia cerebelar, com remanescentes do flóculo e do paraflóculo aderidos às leptomeninges e pedúnculos cerebelares hipoplásicos. Havia hidrocefalia, mais acentuada no ventrículo lateral direito. Próximo ao aqueduto mesencefálico, que estava, também, dilatado, observou-se pequena cavidade cística (porencefalia). O hipocampo estava deslocado verticalmente e atrofiado, e a ponte arredondada no sentido lateral.

Histologicamente, as porções remanescentes do cerebelo apresentavam, em algumas áreas, o córtex desorganizado, a capa granular com menor densidade celular e arranjada em núcleos. As células de Purkinje estavam dispersas na capa granular e na capa molecular e apresentando, em alguns casos, grandes vacúolos intracitoplasmáticos. Em algumas áreas, distinguia-se remanescentes do cerebelo mantendo sua morfologia normal, porém com as capas molecular e granular mais estreitas; esta última com menor densidade celular, e com número de células de Purkinje normal. Porencefalia, observada nos 2 animais, apresentava-se como cavidades císticas delimitadas por astrócitos caracterizando a formação de membrana limitante glial. Nas demais área do SNC, não foram observadas lesões histológicas significativas. Nos cortes corados por azul rápido de luxol, foram observadas áreas focais de desmielinização na substância branca cerebelar. Os resultados da imunoistoquímica, realizada para detecção do vírus da BVD-MD, foram negativos. 


\section{DISCUSSÃO}

Nos dois casos de hipoplasia cerebelar relatados, observou-se uma relação direta entre as lesões macroscópicas e os sinais clínicos apresentados pelos animais e caracterizados por perda de equilíbrio e marcha com os membros afastados, que estão relacionados a lesões no lobo floculonodular (vestibulocerebelo ou arquicerebelo); hipermetria e tremores de intenção, que ocorrem preferentemente quando as lesões são nos hemisférios cerebelares e porção medial do vermis (pontocerebelo ou neocerebelo); e, opistótono e hiperextensão dos membros anteriores, que se relacionam a lesões no vermis do lobo rostral e hemisférios adjacentes (espinocerebelo ou paleocerebelo) (DeLAHUNTA, 1983; KING, 1994). Por outro lado, lesões macroscópicas nem sempre estão presentes em casos de hipoplasia cerebelar, uma vez que a enfermidade tem sido descrita, também, sem diminuição evidente do tamanho do cerebelo e, aparentemente, a intensidade dos sinais clínicos nem sempre reflete a severidade das alterações macroscópicas observadas no cerebelo (O'SULLIVAN \& McPHEE, 1975; KAHRS et al., 1970; JUBB et al., 1993).

Hipoplasia cerebelar, de provável origem hereditária, tem sido descrita na raça Shorthorn com sinais clínicos similares aos observados nos dois terneiros Charolês e lesões macroscópicas caracterizadas por diminuição uniforme do tamanho do cerebelo, circunvoluções achatadas e córtex pequeno, com as folhas cerebelares sem ramificações (FINNIE \& LEAVER, 1965).

Em ambos os casos de hipoplasia cerebelar descritos, observou-se que o cerebelo mantinha, apenas, resquícios da região do flóculo e paraflóculo e uma cavidade, preenchida por líquido, envolvida pelas leptomeninges, que estavam aderidas aos restos cerebelares presentes. Isso parece indicar que houve destruição do tecido cerebelar, do mesmo modo que é descrito em casos de hipoplasia cerebelar causada pela infecção de fêmeas prenhes pelo vírus da BVD-MD (KAHRS et al., 1970; BROWN et al., 1974; WILSON et al., 1983).

As lesões histológicas observadas são similares às encontradas na hipoplasia cerebelar causada pela infecção de fêmeas prenhes pelo vírus da BVD-MD, que se caracterizam por degeneração das folhas e cavitação e, aparentemente, representam lesões residuais resultantes do processo destrutivo do tecido causado pelo vírus, durante a infecção do feto (BROWN et al., 1974). A presença de células de Purkinje aparentemente normais, mesmo nas áreas onde a capa granular apresentava-se com pou- ca densidade celular e desorganizada, parece indicar que o processo patológico inicial atingiu, especialmente, a camada germinativa externa, no momento do desenvolvimento fetal, posterior à completa formação das células que originam os neurônios de Purkinje, ao redor dos 100 dias de gestação (DeLAHUNTA, 1983). Isso é proposto, também, para as lesões encontradas no cerebelo de terneiros cujas mães foram infectadas, experimentalmente, com o vírus da BVD-MD, entre os 100 e os 150 dias de gestação e que foram examinados após o nascimento (BROWN et al., 1974).

$\mathrm{Na}$ hipoplasia cerebelar, provavelmente hereditária, que ocorre na raça Shorthorn, as lesões histológicas caracterizam-se por diminuição do número de células ganglionares da capa granular e capa molecular estreita, número reduzido de células de Purkinje e ausência total das mesmas em algumas áreas, embora algumas folhas cerebelares apresentem aspecto normal (O'SULLIVAN \& McPHEE 1975, SWAN \& TAYLOR 1982). FINNIE \& LEAVER (1965) descrevem, também na raça Shorthorn, lesões histológicas caracterizadas por reduzido número de células ganglionares, capa molecular estreita e número de células de Purkinje normal, algumas apresentando vacúolos no citoplasma, sendo as lesões atribuídas à suspensão do desenvolvimento cerebelar ou ao desenvolvimento cerebelar anormal. Nessa raça, aparentemente, tanto as alterações macroscópicas como histológicas diferem dos casos descritos neste trabalho, já que a presença de cavitações observadas nos dois animais deste estudo sugere que houve destruição do tecido cerebelar, mais do que falha no desenvolvimento normal. SWAN \& TAYLOR (1982) mencionam, também, essas diferenças patológicas entre a enfermidade geneticamente transmitida e a causada pelo vírus da BVD-MD.

Apesar de os resultados da técnica de imuno-histoquímica, utilizada para detecção do vírus da BVD-MD, realizada em cortes do SNC dos dois animais com hipoplasia cerebelar, terem sido negativos, isso não descarta a possibilidade de que esse vírus seja o responsável pelas lesões observadas, uma vez que não existem evidências epidemiológicas que sugiram, nesses casos, que a doença tenha sido geneticamente transmitida.

\section{FONTE DE AQUISIÇÃO}

a Anticorpo monoclonal 15C5, produzido na Universidade de Cornell, Ithaca, NY. Técnica realizada pela Dra. Debora Cesar. DI. LA.VE. Miguel C. Rubino, Montevideo, Uruguai. 


\section{REFERÊNCIAS BIBLIOGRÁFICAS}

BROWN T.T., DeLAHUNTA A., BISTNER S.I., et $\boldsymbol{a}$. Pathogenetic studies of infection of the bovine fetus with bovine viral diarrhea virus. I Cerebellar atrophy. Vet Pathol v.11, p.486-505, 1974.

CESAR D. Deteccion del virus de la diarrea viral bovina en Uruguay. In: ENCONTRO DE LABORATÓRIOS DE DiAGNóstico VeterinÁRIO do CONE SUL, 1, 1996, Campo Grande, MS. Anais... Campo Grande, UFMS, 1996. p.194200.

DelAHUNTA, A. Cerebellum. In: DeLAHUNTA A. Veterinary neuroanatomy and clinical neurology. 2 ed. Philadelphia: Saunders, 1983. p.255-278.

DONE J.T., TERLECKI S., RICHARDSON C., et al. Bovine virus diarrhoea-mucosal disease virus: Pathogenicity for the fetal calf following maternal infection. Vet Rec, v.7, p.473$479,1980$.

FINNIE E.P., LEAVER D.D. Cerebellar hypoplasia in calves. Aust Vet J v.41, p.287-288, 1965.

JUBB K.V.F., HUXTABLE C.R. The nervous system. In: JUBB K.V.F., KENNEDY P.C., PALMER N. Pathology of domestic animals. 4.ed. California: Academic, 1993. v.1, p.267-437.

KAHRS R.F., SCOTT F.W., DeLAHUNTA A. Congenital cerebellar hypoplasia and ocular defects in calves following bovine viral diarrhea-mucosal disease infection in pregnant cattle. J Am Vet Med Assoc v.156, n.10, p.1443-1450, 1970.

KING A.S. Physiological and clinical anatomy of the domestic animals. Oxford : Oxford University, 1994. V.1: Central nervous system, $325 \mathrm{p}$.

O'SULLIVAN B.M., McPHEE C.P. Cerebellar hypoplasia of genetic origen in calves. Aust Vet J, v.51, p.469-471, 1975.

RIET-CORREA F., MOOJEN V., ROEHE P.M., et al. Viroses confundíveis com febre aftosa. Ciência Rural v.26, n.2, p.323-332, 1996.

SWAN R.A., TAYLOR E.G. Cerebellar hypoplasia in beef Shorthorn calves. Aust Vet J v.59, p.95-96, 1982.

WILSON T.M., DeLAHUNTA A., CONFER L. Cerebellar degeneration in dairy calves: clinical, pathologic, and serologic features of an epizootic caused by bovine viral diarrhea virus. J Am Vet Med Assoc v.183, n.5, p.544-547, 1983.

Ciência Rural, v. 31, n. 1, 2001. 